

\title{
Keywords
}

affective influence; appraisal; emotional structure; unconscious

\begin{abstract}
Affective reactions are generally about something, and in our article, we focused on two different kinds of affective objects. One, the intentional object, gives direction to emotions, as when one's anger is directed toward one person rather than another. The other kind of object, which might be called the defining object, is important in differentiating among emotions. Thus, fear is an affective reaction that takes as its object a possible undesirable outcome, whereas sadness is an affective reaction that takes as its object an actual undesirable outcome. Fear and sadness differ in many ways, of course, but all, we suggest, reflect the fact that they have slightly different psychological situations as their defining objects.
\end{abstract}

Our article has three parts. First, we reviewed research showing that the impact of mood and emotion on cognition depends on what they modify. Consistent with the affect-asinformation hypothesis (e.g., Clore \& Huntsinger, 2007; Schwarz \& Clore, 2007), we found that usually reliable mood effects could be reversed by making new objects cognitively

(C) 2009 SAGE Publications and The International Society for Research on Emotion

Corresponding author: Gerald L. Clore, Department of Psychology, 102 Gilmer Hall, University of Virginia, P.O. Box 400400, Charlottesville, VA 22904, USA. gclore@ virginia.edu. 
accessible. Second, from an appraisal theory perspective (e.g., Ortony, Clore, \& Collins, 1988), we noted that emotions are defined by their objects, as described above. And third, relevant to both, we examined how unconscious, uncertain, abstract, or symbolic objects can enhance the power and influence of emotion. Two sets of commentaries provided interesting and useful perspectives on what we said. We turn first to two comments by Cunningham and Van Bavel.

\section{Morality and Disgust}

Cunningham and Van Bavel argue that our account should distinguish between core disgust and moral disgust, which it currently does not. The OCC account does separate emotions concerning blameworthy actions (e.g., reproach) from those concerning unappealing objects (e.g., disgust), but certain immoral actions do seem likely to involve both. For example, engaging in incest is a violation of any number of moral standards, leading to, say, reproach, but the idea of incest is also disgusting. In contrast, a more mundane action-lying to escape punishment-is blameworthy, but not disgusting. We reported data that disgust can influence moral judgments (Schnall, Haidt, Clore, \& Jordan, in press). Thus, core disgust plus potentially blameworthy actions may yield something like moral disgust. Moral disgust might be accommodated in the OCC model by positing that some emotions can reflect a joint focus on actions and objects, including in this case, disapproval of engaging in a blameworthy action and dislike of the action as a distasteful object. There is precedence for this in the model, in the treatment of a group emotion that includes anger as involving a joint focus on (undesirable) outcomes and (blameworthy) actions.

\section{Comparisons not Objects}

Cunningham and Van Bavel suggest that type of computation rather than type of object may best distinguish emotions. Thus, some emotions involve comparing present with past, present with future, expected with actual outcomes, and so on. We note that the OCC account includes these distinctions. Thus, for example, hope, fear, disappointment, and relief all involve the prospect of (future) good or bad outcomes, whereas sadness and grief involve past outcomes, and so on. We did not give a full account of the OCC model (see Ortony et al., 1988), but it parallels the account they propose in important respects. We should also note that many of the distinctions that lead to emotion differentiation in the OCC model are directly perceived, rather than being objects of deliberation. These include whether an outcome was mine or someone else's, whether I or another was the actor, whether the outcome is in the future or the past, and so on. Thus, although some emotional reactions implicate higher cognitive processes, many do not.

We turn next to three points by Piotr Winkielman, who also focused on the portion of our article on emotion appraisal.

\section{Cognition versus Embodiment}

Winkielman complains that we use the word "embodied," but propose a model that is symbolic. Actually, we used the word "embodied" not for the OCC account of emotion structure, as he suggests, but for the affect-as-information account of emotional influence. In 
that context, the term "embodied information" is intended to forestall assumptions that "information" refers only to conceptual information, rather than to embodied and experienced information, as well. But our account draws on two different models with different functions, and the OCC appraisal model is not about embodiment.

The OCC account is a rule-based account of the deep structure of the kinds of situations that elicit specific emotions. It is not about emotional processes and does not assume that people consult rules before feeling emotions. Similarly, people do not consult principles of aesthetics before being pleased by beauty, rules of syntax before speaking, or legal principles before perceiving injustice. There is often confusion about the difference between claims about the structure of such domains and those about how people negotiate them. As noted in another context (Clore, Storbeck, Robinson, \& Centerbar, 2005, p. 402):

Failure to make such distinctions would lead one to conclude that only linguists can speak, only lawyers know the difference between right and wrong, and only appraisal theorists can feel emotions. But the rules of syntax, the rules of law, and the rules of appraisal theory are assertions about the structure of utterances, of justice, and of emotion, respectively. They are not process models of speaking, judging, or feeling, even though they are basic for understanding those processes. As particular kinds of evaluations, emotions necessarily involve some sort of appraisal, but the term carries no implications about how such evaluations are made.

\section{Unconscious Processing}

Winkielman proposes that unconscious affective stimuli have special access to basic emotional and motivational processes. We too are interested in the curious power of unconscious affect. However, we view it as powerful mainly because when the proper object of affect is kept from awareness, affect is left without situational constraints on its meaning and applicability.

\section{Cold Cognition}

Winkielman suggests that ours is a "cold" cognitive account. Actually, our article was partly motivated by a realization of how cognitive transformations of affective objects can heat up emotions. Unlike the family dog that remains unmoved by insults, innuendo, or abstractions about honor, humans transform words and ideas into powerful emotional triggers that can move them to extreme behavior. As a result, we affective scientists may never understand the sorrow and the pity of human suffering nor the power and the glory of human possibilities unless we augment reductive models of emotion with considerations of emotional cognition.

\section{Acknowledgments}

Support is acknowledged from National Institute of Mental Health grant MH 50074 and National Science Foundation grant BCS 0518835. 


\section{References}

Clore GL, Huntsinger JR. How emotions inform judgment and regulate thought. Trends in Cognitive Science. 2007; 11:393-399.

Clore, GL.; Storbeck, J.; Robinson, MD.; Centerbar, D. Seven sins of research on unconscious affect. In: Barrett, LF.; Niedenthal, P.; Winkielman, P., editors. Emotion and consciousness. New York: Guilford; 2005. p. 384-408.

Ortony, A.; Clore, GL.; Collins, A. The cognitive structure of emotions. New York: Cambridge University Press; 1988.

Schnall S, Haidt J, Clore GL, Jordan AH. Disgust as embodied moral judgment. Personality and Social Psychology Bulletin. in press.

Schwarz, N.; Clore, GL. Feelings and phenomenal experiences. In: Higgins, ET.; Kruglanski, A., editors. Social psychology. A handbook of basic principles. 2. New York: Guilford Press; 2007. p. 385-407. 